\title{
Proton-Pump Inhibitor vs. H2-Receptor Blocker Use and Overall Risk of CKD Progression
}

\section{Liza Cholin ( $\nabla$ cholinl@ccf.org )}

Cleveland Clinic

\section{Tarek Ashour}

Cleveland Clinic

Ali Mehdi

Cleveland Clinic

Jonathan Taliercio

Cleveland Clinic

\section{Remy Daou}

Saint Joseph University

\section{Susana Arrigain}

Cleveland Clinic

Jesse Schold

Cleveland Clinic

\section{George Thomas}

Cleveland Clinic

Joseph Nally

Cleveland Clinic

\section{Nazih Nakhoul}

Tulane Medical Center

\section{Georges Nakhoul}

Cleveland Clinic

\section{Research Article}

Keywords: proton-pump inhibitors, histamine-2 receptor blockers, chronic kidney disease, disease progression, mortality

Posted Date: December 21st, 2020

DOl: https://doi.org/10.21203/rs.3.rs-128467/v1

License: (9) This work is licensed under a Creative Commons Attribution 4.0 International License. 
Version of Record: A version of this preprint was published at BMC Nephrology on July 15th, 2021. See the published version at https://doi.org/10.1186/s12882-021-02449-0. 


\section{Abstract}

Background: The relationship between proton-pump inhibitor (PPI) use and chronic kidney disease (CKD) progression remains controversial. Specifically, there is a lack of data evaluating renal outcomes in established CKD patients. The aim of our study is to determine the risk of progression to end-stage kidney disease (ESKD) or death amongst CKD patients on PPI, histamine-2 receptor blocker (H2B), or no antiacid therapy.

Methods: Using our CKD registry, we evaluated the relationship between PPI and H2B use and outcomes amongst patients with CKD (eGFR <60), with at least 2 PCP visits in the year prior. A Cox proportional hazards model was used to evaluate the relationship between medication groups and overall mortality, while competing risks regression models were used to determine the risk of ESKD with death as a competing risk.

Results: 25,455 patients met inclusion criteria and were stratified according to medication group: no antacid therapy $(15,961)$, PPI use $(8,646)$, or H2B use (848). At 4 years, the cumulative incidence of ESKD with death as a competing risk was $2.0 \%(95 \% \mathrm{Cl}: 1.7,2.4), 1.5 \%(0.8,2.8)$, and $1.6 \%(1.4,1.9)$ among PPI, $\mathrm{H} 2 \mathrm{~B}$, and no medication respectively $(\mathrm{P}=0.22)$. The cumulative incidence of death with $\mathrm{ESKD}$ as a competing risk was $17.6 \%(95 \% \mathrm{Cl}$ : $16.6,18.6), 16.7 \%(13.7,19.8)$, and $17.3 \%(16.6,18.0)(P=0.71)$.

Conclusions: Use of PPI in a CKD population was not associated with increased mortality or progression to ESKD when compared to $\mathrm{H} 2$ blocker and to no acid suppressing therapy.

\section{Introduction}

Since the introduction of Omeprazole in 1989, Proton Pump Inhibitors (PPIs) have gone on to become one of the most widely prescribed medications in the United States. These drugs are also increasingly sold over the counter (OTC), making the actual use of PPIs across the general population much higher. Initially praised for their superiority in treating many acid-related disorders, PPIs have more recently garnered scrutiny over their potential adverse effects. ${ }^{1,2}$ Acute kidney injury (AKI) associated with PPI use is well documented in the literature. Case reports and small case series initially described the development of acute interstitial nephritis (AIN) in patients prescribed PPIs. ${ }^{3,4}$ Since that time, there have been various large observational studies and meta-analyses which have reproduced the same findings of increased risk of developing AKI with PPI use. 5, 6, 7, 8, 9

More recently, some studies have suggested an increased risk of developing chronic kidney disease (CKD) among patients with normal renal function. ${ }^{10,11,12,13,14}$ However, the data on this correlation remains limited and controversial. In the first systematic review and meta-analysis paper to look at PPI use and adverse renal outcomes, the subgroup analysis found no association between PPI use and risk of CKD in older patients (age $>62$ years), in studies with large sample sizes ( $>10,000$ participants), in case-control studies, and in the US study location (3 out of the 4 studies reviewed). ${ }^{15}$ Even sparser are the 
studies illustrating the relationship between PPI use and renal outcomes in patients with already established CKD. To the best of our knowledge, only one such study has been published. ${ }^{16}$ It concluded that PPI use was associated with increased major renal adverse events, defined as doubling of serum creatinine or progression to end-stage renal disease.

Given the inconclusive data on PPI safety in the CKD population, we elected to examine the rate of CKD progression among CKD patients on PPI versus Histamine-2-Receptor Blockers (H2B) and to no acidsuppressing therapy.

\section{Materials And Methods Patient population}

We used data from our Electronic Health Record (EHR) - based Chronic Kidney Disease (CKD) registry to evaluate the relationship between the use of proton-pump inhibitors (PPI) and $\mathrm{H} 2$ blockers and outcomes. We have previously described the development and validation of this registry. ${ }^{17}$ For the current analysis, we included patients who: a) had at least one face-to-face outpatient encounter with a Cleveland Clinic health care provider and at least two estimated glomerular filtration rate (eGFR) measures < $60 \mathrm{ml} / \mathrm{min} / 1.73 \mathrm{~m}^{2},>90$ days apart, between January 1, 2007 and December 30, 2017 and patients who were not on dialysis nor had a functioning kidney transplant, b) had active PPI and no prior H2B prescription, or had active $\mathrm{H} 2 \mathrm{~B}$ and no prior PPI prescription, or had neither prior PPI nor prior $\mathrm{H} 2 \mathrm{~B}$ on the date of second eGFR $<60$ (CKD), c) were residents of the State of Ohio, and d) had continuity of care at our institution with at least 2 PCP visits in the year prior to the second eGFR $<60$.

\section{Patient Characteristics}

We extracted demographic information from the EHR, and defined comorbid conditions such as diabetes mellitus, hypertension, coronary artery disease, malignancy, congestive heart failure, and hyperlipidemia using pre-specified and previously validated criteria. ${ }^{17}$ We evaluated whether these conditions existed prior to the second eGFR $<60 \mathrm{ml} / \mathrm{min} / 1.73 \mathrm{~m}^{2}$. We also extracted relevant laboratory data (serum albumin, potassium and bicarbonate) from the EHR. For laboratory results, the last outpatient laboratory result obtained within 2 years prior to inception was included.

We evaluated whether patients had continuity of care at our institution by searching for 2 completed visits or appointments with the listed primary care provider (PCP) within the year prior to the second eGFR $<60 \mathrm{ml} / \mathrm{min} / 1.73 \mathrm{~m}^{2}$.

\section{Kidney function}

All serum creatinine measurements were done in the same laboratory using a Hitachi D 2400 Modular Chemistry Analyzer (Roche Diagnostics, Indianapolis, IN). We estimated eGFR using the CKD-EPI equation. ${ }^{18}$ CKD was classified into the following stages: stage 3 CKD (eGFR $30-59 \mathrm{ml} / \mathrm{min} / 1.73 \mathrm{~m}^{2}$ ), 
stage 4 CKD (eGFR 15-29 ml/min $/ 1.73 \mathrm{~m}^{2}$ ), and stage 5 CKD (eGFR $\left.<15 \mathrm{ml} / \mathrm{min} / 1.73 \mathrm{~m}^{2}\right)$. We further categorized stage 3 into CKD stage $3 a$ (eGFR $45-59 \mathrm{ml} / \mathrm{min} / 1.73 \mathrm{~m}^{2}$ ) and stage $3 \mathrm{~b}$ (eGFR $30-$ $44 \mathrm{ml} / \mathrm{min} / 1.73 \mathrm{~m}^{2}$ ).

\section{Proton Pump Inhibitors and H2 blockers}

Prescriptions for PPI and H2B were obtained for all patients from the EHR. The prescriptions were written by the medical providers, and we could not verify with area pharmacies whether the prescriptions were filled. When a prescription had a start date before the second eGFR $<60$ and an end date after that second eGFR $<60$, the prescription was considered active. Patients were grouped into mutually exclusive groups on the date of second eGFR < 60: a) active PPI and no record of prior $\mathrm{H} 2 \mathrm{~B}, \mathrm{~b}$ ) active $\mathrm{H} 2 \mathrm{~B}$ and no prior PPI, or C) no prior PPI or H2B.

\section{Outcomes}

Our outcomes were mortality and end-stage kidney disease (ESKD) with death as a competing risk. We ascertained dates of death from the EHR as well as through linkage of the CKD registry with the Ohio Department of Health death records. We ascertained ESKD through linkage of our CKD registry with the United States Renal Data Services (USRDS). Deaths and ESKD were obtained up to end of 2017.

\section{Statistical analysis}

We compared baseline characteristics among patients with PPI, H2B and no medication using Chi-square, ANOVA and Kruskal-Wallis tests for categorical and continuous variables, respectively. We estimated Kaplan-Meier survival over time by medication group and also the cumulative incidence function of ESKD with death as a competing risk, and the cumulative incidence function of death with ESKD as a competing risk.

We evaluated the relationship between medication group and overall mortality using a Cox proportional hazards models and the relationship between medication group and progression to ESKD using competing risks regression models as described by Fine and Gray. ${ }^{19}$ We adjusted the models for the following covariates: age, race, sex, eGFR, BMI group, hemoglobin, potassium, $\mathrm{CO} 2$, diabetes, hypertension, CVD, PVD,CAD, CHF, malignancy, ACEI/ARB, beta blockers, smoking and insurance. We used splines for continuous covariates when appropriate. We tested an interaction between CKD stage and PPI group excluding $\mathrm{H} 2 \mathrm{~B}$ patients. We excluded $\mathrm{H} 2 \mathrm{~B}$ patients because there were not many in advanced stages of CKD. We used splines to relax linearity assumptions as necessary.

We had missing data for the following percent of patients: 1\% missing BMI and smoking, $16 \%$ hemoglobin, $0.2 \%$ potassium and bicarbonate, and $3 \%$ insurance data. We used multiple imputations (SAS proc MI) with the Markov Chain Monte Carlo method and a single chain to impute 5 datasets with complete continuous and binary data in a first step, and then in a second step we imputed insurance group on each of the 5 datasets using discriminant function analysis. All the covariates from the 
multivariable model were included in the imputation. We fit the models on each of the 5 imputed datasets, and parameter estimates were combined using SAS MI analyze.

All analyses were conducted using Linux SAS version 9.4 (SAS Institute, Cary, NC), and graphs were created using R 3.5.1 (The R Foundation for Statistical Computing, Vienna, Austria). This study and the CKD registry were both approved by the Cleveland Clinic Institutional Review Board.

\section{Results}

Out of 96,436 patients that entered the CKD registry between 2007 and 2017, there were 86,697 that were residents of Ohio (Fig. 1). Of those, 25,455 had 2 PCP visits in the year prior and fulfilled all inclusion criteria. Among them, 8,646 had active PPI with no prior H2B, 848 had active H2B with no prior PPI, and 15,961 had neither medication. Patients on the different medication groups were significantly different on several characteristics (Table 1). Most notably, patients on PPI and H2B were less likely to be male, more likely to be obese and more likely to be on Medicare. Those on PPI were also more likely to have CAD and CHF. 
Table 1

Patient characteristics by medication group

\begin{tabular}{|c|c|c|c|c|c|c|}
\hline Factor & $\begin{array}{l}\mathrm{N} \\
\text { missing }\end{array}$ & $\begin{array}{l}\text { Overall ( } \mathrm{N}= \\
25,455)\end{array}$ & $\begin{array}{l}\text { None } \\
(N=15,961)\end{array}$ & $\begin{array}{l}\text { PPI } \\
(N=8,646)\end{array}$ & $\begin{array}{l}\mathrm{H} 2 \\
(\mathrm{~N}=848)\end{array}$ & $\begin{array}{l}\text { p- } \\
\text { value }\end{array}$ \\
\hline Age & 0 & $73.2 \pm 11.0$ & $73.4 \pm 11.1$ & $72.8 \pm 10.9$ & $73.2 \pm 11.4$ & $0.001^{a}$ \\
\hline Male Sex & 0 & $10,722(42.1)$ & $7,092(44.4)$ & $3,322(38.4)$ & $308(36.3)$ & $\begin{array}{l}< \\
0.001^{c}\end{array}$ \\
\hline African American & 0 & $2,982(11.7)$ & $1,896(11.9)$ & $970(11.2)$ & 116(13.7) & $0.060^{c}$ \\
\hline Smoke & 0 & & & & & $\begin{array}{l}< \\
0.001^{c}\end{array}$ \\
\hline No & & $23,190(91.1)$ & $14,486(90.8)$ & 7,938(91.8) & 766(90.3) & \\
\hline Yes & & $2,035(8.0)$ & $1,300(8.1)$ & $663(7.7)$ & $72(8.5)$ & \\
\hline Missing & & $230(0.90)$ & $175(1.1)$ & $45(0.52)$ & $10(1.2)$ & \\
\hline BMI & 270 & $30.1 \pm 6.7$ & $29.8 \pm 6.6$ & $30.5 \pm 6.7$ & $30.7 \pm 7.3$ & $\begin{array}{l}< \\
0.001^{\mathrm{a}}\end{array}$ \\
\hline BMI group & 0 & & & & & $\begin{array}{l}< \\
0.001^{c}\end{array}$ \\
\hline$<18.5 \mathrm{~kg} / \mathrm{m} 2$ & & 295(1.2) & 204(1.3) & $82(0.95)$ & $9(1.1)$ & \\
\hline $\begin{array}{l}18.5- \\
24.9 \mathrm{~kg} / \mathrm{m} 2\end{array}$ & & $5,203(20.4)$ & $3,475(21.8)$ & $1,551(17.9)$ & 177(20.9) & \\
\hline $25-29.9 \mathrm{~kg} / \mathrm{m} 2$ & & 8,638(33.9) & $5,446(34.1)$ & $2,941(34.0)$ & 251(29.6) & \\
\hline $30-34.9 \mathrm{~kg} / \mathrm{m} 2$ & & $6,064(23.8)$ & $3,654(22.9)$ & $2,207(25.5)$ & 203(23.9) & \\
\hline $35-39.9 \mathrm{~kg} / \mathrm{m} 2$ & & $2,872(11.3)$ & $1,703(10.7)$ & $1,051(12.2)$ & 118(13.9) & \\
\hline $40+\mathrm{kg} / \mathrm{m} 2$ & & $2,113(8.3)$ & $1,275(8.0)$ & $760(8.8)$ & $78(9.2)$ & \\
\hline Missing & & $270(1.1)$ & 204(1.3) & $54(0.62)$ & $12(1.4)$ & \\
\hline eGFR & 0 & $50.0 \pm 9.2$ & $50.1 \pm 9.1$ & $49.8 \pm 9.5$ & $49.2 \pm 9.0$ & $0.004^{a}$ \\
\hline CKD stage & 0 & & & & & $0.021^{\mathrm{c}}$ \\
\hline 3a. $45-59$ & & $19,584(76.9)$ & $12,333(77.3)$ & $6,619(76.6)$ & $632(74.5)$ & \\
\hline 3b. $30-44$ & & $4,703(18.5)$ & $2,940(18.4)$ & $1,582(18.3)$ & 181(21.3) & \\
\hline
\end{tabular}

Statistics presented as Mean \pm SD, Median [P25, P75] or N (column \%).

p-values: $a=$ ANOVA, $b=$ Kruskal-Wallis test, $c=$ Pearson's chi-square test. 


\begin{tabular}{|c|c|c|c|c|c|c|}
\hline Factor & $\begin{array}{l}\mathbf{N} \\
\text { missing }\end{array}$ & $\begin{array}{l}\text { Overall }(\mathrm{N}= \\
25,455)\end{array}$ & $\begin{array}{l}\text { None } \\
(N=15,961)\end{array}$ & $\begin{array}{l}\text { PPI } \\
(N=8,646)\end{array}$ & $\begin{array}{l}\mathrm{H} 2 \\
(\mathrm{~N}=848)\end{array}$ & $\begin{array}{l}\mathrm{p}- \\
\text { value }\end{array}$ \\
\hline 4. $15-29$ & & $1,054(4.1)$ & $624(3.9)$ & $400(4.6)$ & $30(3.5)$ & \\
\hline 5. $<15$ & & $114(0.45)$ & $64(0.40)$ & $45(0.52)$ & $5(0.59)$ & \\
\hline Diabetes & 0 & 8,695(34.2) & $5,276(33.1)$ & $3,108(35.9)$ & $311(36.7)$ & $\begin{array}{l}< \\
0.001^{c}\end{array}$ \\
\hline Malignancy & 0 & $5,889(23.1)$ & $3,646(22.8)$ & $2,084(24.1)$ & 159(18.8) & $<.001^{c}$ \\
\hline Hypertension & 0 & $24,775(97.3)$ & $15,487(97.0)$ & $8,462(97.9)$ & $826(97.4)$ & $\begin{array}{l}< \\
0.001^{c}\end{array}$ \\
\hline Hyperlipidemia & 0 & $22,525(88.5)$ & $14,012(87.8)$ & 7,764(89.8) & 749(88.3) & $<.001^{c}$ \\
\hline $\begin{array}{l}\text { Coronary artery } \\
\text { disease }\end{array}$ & 0 & $5,340(21.0)$ & $2,910(18.2)$ & $2,243(25.9)$ & 187(22.1) & $\begin{array}{l}< \\
0.001^{c}\end{array}$ \\
\hline $\begin{array}{l}\text { Congestive heart } \\
\text { failure }\end{array}$ & 0 & $2,194(8.6)$ & $1,175(7.4)$ & $941(10.9)$ & 78(9.2) & $\begin{array}{l}< \\
0.001^{c}\end{array}$ \\
\hline $\begin{array}{l}\text { Cerebrovascular } \\
\text { Disease }\end{array}$ & 0 & $2,974(11.7)$ & 1,692(10.6) & $1,170(13.5)$ & 112(13.2) & $\begin{array}{l}< \\
0.001^{c}\end{array}$ \\
\hline PVD & 0 & $1,387(5.4)$ & $786(4.9)$ & $555(6.4)$ & $46(5.4)$ & $\begin{array}{l}< \\
0.001^{c}\end{array}$ \\
\hline ACE/ARB & 0 & $18,403(72.3)$ & $11,445(71.7)$ & 6,354(73.5) & 604(71.2) & $0.009^{c}$ \\
\hline Diuretics & 0 & $18,029(70.8)$ & $11,071(69.4)$ & $6,354(73.5)$ & $604(71.2)$ & $<.001^{c}$ \\
\hline Statin & 0 & $17,385(68.3)$ & $10,498(65.8)$ & $6,302(72.9)$ & $585(69.0)$ & $\begin{array}{l}< \\
0.001^{c}\end{array}$ \\
\hline Beta Blockers & 0 & $14,467(56.8)$ & $8,508(53.3)$ & $5,433(62.8)$ & $526(62.0)$ & $\begin{array}{l}< \\
0.001^{\mathrm{c}}\end{array}$ \\
\hline Albumin & 3359 & $4.1 \pm 0.36$ & $4.2 \pm 0.35$ & $4.1 \pm 0.38$ & $4.1 \pm 0.35$ & $\begin{array}{l}<.001^{\mathrm{a}} \\
\end{array}$ \\
\hline Hemoglobin & 4019 & $13.1 \pm 1.7$ & $13.3 \pm 1.7$ & $12.8 \pm 1.7$ & $13.0 \pm 1.7$ & $\begin{array}{l}<.001^{\mathrm{a}} \\
\end{array}$ \\
\hline
\end{tabular}

Statistics presented as Mean \pm SD, Median [P25, P75] or N (column \%).

p-values: $a=$ ANOVA, $b=$ Kruskal-Wallis test, $c=$ Pearson's chi-square test. 


\begin{tabular}{|c|c|c|c|c|c|c|}
\hline Factor & $\begin{array}{l}\mathrm{N} \\
\text { missing }\end{array}$ & $\begin{array}{l}\text { Overall }(\mathrm{N}= \\
25,455)\end{array}$ & $\begin{array}{l}\text { None } \\
(N=15,961)\end{array}$ & $\begin{array}{l}\text { PPI } \\
(N=8,646)\end{array}$ & $\begin{array}{l}\mathrm{H} 2 \\
(\mathrm{~N}=848)\end{array}$ & $\begin{array}{l}\text { p- } \\
\text { value }\end{array}$ \\
\hline Proteinuria & 12298 & $3,190(24.2)$ & $2,013(25.1)$ & $1,075(22.9)$ & 102(23.0) & $0.014^{c}$ \\
\hline $\mathrm{CO} 2$ & 64 & $25.8 \pm 3.0$ & $25.8 \pm 3.0$ & $25.7 \pm 3.2$ & $25.8 \pm 3.1$ & $0.007^{a}$ \\
\hline Potassium & 51 & $4.4 \pm 0.50$ & $4.4 \pm 0.49$ & $4.4 \pm 0.51$ & $4.4 \pm 0.51$ & $0.36^{\mathrm{a}}$ \\
\hline Urine ph & 14759 & $6.0[5.0,6.5]$ & $6.0[5.0,6.5]$ & $6.0[5.0,6.5]$ & $6.0[5.0,6.0]$ & $0.57^{b}$ \\
\hline $\begin{array}{l}\text { Insurance } \\
\text { grouped }\end{array}$ & 0 & & & & & $\begin{array}{l}< \\
0.001^{c}\end{array}$ \\
\hline Medicaid & & $434(1.7)$ & $229(1.4)$ & 189(2.2) & $16(1.9)$ & \\
\hline Medicare & & $18,508(72.7)$ & $11,397(71.4)$ & $6,463(74.8)$ & 648(76.4) & \\
\hline Missing & & $760(3.0)$ & 492(3.1) & $249(2.9)$ & $19(2.2)$ & \\
\hline Other & & $5,753(22.6)$ & $3,843(24.1)$ & $1,745(20.2)$ & $165(19.5)$ & \\
\hline \multicolumn{7}{|c|}{ Statistics presented as Mean \pm SD, Median [P25, P75] or N (column \%). } \\
\hline p-values: a & $b=$ Krus & Wallis test, $c=$ & earson's chi-sc & re test. & & \\
\hline
\end{tabular}

\section{Mortality}

During a median follow up of 4.14 years, there were 5,562 deaths. At 1-year the Kaplan-Meier all-cause mortality survival estimates were $96.1(95.8,96.4), 96.3(95.9,96.7)$ and $98.0(97.0,99.0)$ for the no medication, PPI and H2B groups respectively. At 4 years, survival was $82.2(81.5,82.9), 81.8(80.8,82.8)$ and $83.0(79.9,86.1)$ respectively $(P=0.56)$. Table 2 shows results from the adjusted Cox mortality model. When adjusted for comorbidities and laboratory results, medication group was not significantly associated with hazard of death. The interaction between CKD stage and PPI vs. no medication (excluding $\mathrm{H} 2 \mathrm{~B}$ ) was not significant $(\mathrm{P}=0.96)$ suggesting that the relationship between $\mathrm{PPI}$ and mortality is not different across different CKD stages. 
Table 2

Adjusted models: Cox model of mortality and Competing risks Regression models of ESKD and Death

\begin{tabular}{|c|c|c|c|c|c|c|}
\hline \multirow[t]{3}{*}{$\begin{array}{l}\text { Medication } \\
\text { group }\end{array}$} & $\begin{array}{l}\text { Cox } \\
\text { model of } \\
\text { Mortality }\end{array}$ & \multirow[t]{3}{*}{$\begin{array}{l}\mathrm{P}- \\
\text { value }\end{array}$} & $\begin{array}{l}\text { Competing Risks } \\
\text { ESKD with death as } \\
\text { competing risk }\end{array}$ & \multirow[t]{3}{*}{$\begin{array}{l}\mathrm{P} \text { - } \\
\text { value }\end{array}$} & $\begin{array}{l}\text { Competing Risks } \\
\text { Death with ESKD as } \\
\text { competing risk }\end{array}$ & \multirow[t]{3}{*}{$\begin{array}{l}\mathrm{P} \text { - } \\
\text { value }\end{array}$} \\
\hline & \multirow{2}{*}{$\begin{array}{l}\mathrm{HR}(95 \% \\
\mathrm{Cl}) \\
(\mathrm{N}= \\
25,455)\end{array}$} & & \multirow{2}{*}{$\begin{array}{l}\text { SHR }(95 \% \mathrm{Cl}) \\
(\mathrm{N}=25,455)\end{array}$} & & \multirow{2}{*}{$\begin{array}{l}\text { SHR }(95 \% \mathrm{Cl}) \\
(\mathrm{N}=25,455)\end{array}$} & \\
\hline & & & & & & \\
\hline $\begin{array}{l}\text { PPI vs. } \\
\text { none }\end{array}$ & $\begin{array}{l}0.97 \\
(0.91 \\
1.03)\end{array}$ & 0.29 & $0.93(0.75,1.15)$ & 0.49 & $0.96(0.90,1.02)$ & 0.15 \\
\hline $\begin{array}{l}\text { H2 vs. } \\
\text { none }\end{array}$ & $\begin{array}{l}0.99 \\
(0.86 \\
1.15)\end{array}$ & 0.90 & $1.07(0.67,1.73)$ & 0.77 & $1.01(0.87,1.17)$ & 0.95 \\
\hline PPI vs. H2 & $\begin{array}{l}0.98 \\
(0.84 \\
1.13)\end{array}$ & 0.77 & $0.87(0.53,1.42)$ & 0.57 & $0.95(0.82,1.11)$ & 0.53 \\
\hline
\end{tabular}

*Adjusted for age, race, sex, eGFR (mortality model only), BMI group, hemoglobin, potassium, $\mathrm{CO}$, diabetes, hypertension, CVD, PVD,CAD, CHF, malignancy, ACE/ARB, beta blockers, smoking and insurance

All adjusted models used 5 datasets created with multiple imputation and MI analyze to obtain the HR or SHR

\section{Progression to ESKD with death as a competing risk}

With a median follow up of 4.1 years, there were 452 ESKD events and 5,362 deaths. In unadjusted analysis, the cumulative incidence of ESKD with death as a competing risk was not significantly different across groups ( $\mathrm{P}=0.22$, Fig. 2$)$. At 4 years, it was $2.0 \%$ among $\mathrm{PPI}(95 \% \mathrm{Cl}: 1.7,2.4), 1.5 \%$ among $\mathrm{H} 2 \mathrm{~B}$ $(95 \% \mathrm{Cl}: 0.8,2.8)$, and $1.6 \%$ among those with neither medication ( $95 \% \mathrm{Cl}: 1.4,1.9)$. The cumulative incidence of death with ESKD as a competing risk was also not significantly different across groups ( $\mathrm{P}=$ 0.71). At 4 years, it was $17.6 \%$ among PPI $(95 \% \mathrm{Cl}: 16.6,18.6), 16.7 \%$ among $\mathrm{H} 2 \mathrm{~B}(95 \% \mathrm{Cl}: 13.7,19.8)$, and $17.3 \%$ among those with neither medication $(95 \% \mathrm{Cl}: 16.6,18.0)$.

In an adjusted competing risks regression model, medication group was not significantly associated with ESKD while considering death as a competing risk (Table 2). Medication group was also not significantly associated with death while considering ESKD as a competing risk. The interaction between CKD stage and medication group (excluding H2B) was not significant in the model of ESKD with death as a competing risk $(P=0.11)$, or in the model of death with ESKD as a competing risk $(P=0.80$, Fig. 2$)$. The lack of interaction suggests the association between medication group and outcomes is not different across CKD stages.

\section{Discussion}


Our study shows that in a population of established stage III to V CKD, there is no association between use of PPI, use of H2-Receptor Blockers and progression to ESKD. The study further determined that there is no difference between the medication groups in overall mortality.

Concerning the progression to ESKD, our results are in contrast to the findings of several other large cohort studies looking at incidence of CKD and rate of CKD progression among PPI users. Several important differences could explain why our findings were different. First, our study was specifically looking at patients with reduced eGFR at baseline (i.e. established CKD patients), while most other cohorts analyzed patients with normal baseline renal function. ${ }^{10,11,12,14}$ In the Klatte study, although patients with reduced renal function were not excluded, the median eGFR was 94.2 and $88.6 \mathrm{ml} / \mathrm{min} / \mathrm{m} 2$ in the H2B and PPI groups, respectively. ${ }^{13}$ The Xie study also had limitations that made interpreting the data difficult. In the earlier follow up period, the study suggested an increased risk of incident CKD and CKD progression; however, after 720 days, the risk of declining renal function actually started to decrease in the PPI group. ${ }^{12}$ The Klatte and Xie studies were also later compiled in a meta-analysis review, which found no association between PPI use and adverse renal outcomes in the subgroup analysis Sect. ${ }^{15}$ The study done by Grant and colleagues concluded that PPI use is associated with increased risk of major adverse renal events. ${ }^{16}$ This study is the only other study, to date, to look at PPI safety specifically in the CKD population. However, there are several important distinctions between Grant's study and our own, which could account for the differences seen in our results. First, there was a large portion of patients excluded from the original cohort (50\%), which could have led to a selection bias. Second, the baseline characteristics were different amongst the two groups tested. The PPI group had more patients with lower eGFR, more proteinuria, and higher prevalence of myocardial infarction and diabetes. These characteristics are known CKD risk factors; therefore, some of the positive association with PPI use and adverse renal outcomes could actually be due to the PPI group being sicker at baseline.

Correlation between PPI use and increased all-cause mortality also remains controversial. Studies discussing this potential risk analyzed patients with cancer, liver cirrhosis, chronic kidney disease, and patients requiring tube feeds. One study determined excess mortality with new PPI use after cancer diagnosis, but not in patients that were continuing users. ${ }^{20}$ This raises the question of whether there were confounding variables that could have been responsible for the difference in mortality, rather than the initiation of PPIs themselves. Two, small cohort studies on patients with liver cirrhosis and bedridden patients requiring tube feeds also showed a positive association with PPI use and increased overall mortality. ${ }^{21,22}$ However, another larger cohort study showed decreased 90 day mortality in hip fracture patients who were started on PPIs during their hospital stay. ${ }^{23}$ Yet another study done by Xie and colleagues showed a small excess of cause specific mortality due to cardiovascular disease, chronic kidney, disease, and upper gastrointestinal cancer in patients taking PPIs. ${ }^{24}$ Although, when Grant looked at the CKD population specifically, no correlation between PPI use and increased mortality could be found. Overall, the reports to date have major limitations including the observational nature of the studies and the degree of illness in the cohorts analyzed. Our study could find no association between PPI use and overall mortality when assessing patients with pre-established CKD. 
Strengths of this analysis include a diverse population of stage III-V CKD, availability of several confounding factors, and the inclusion of patients with at least 2 PCP visits. By only including patients with at least 2 PCP visits, we ensured continuity of care, medication reconciliation and verification of continued acid-suppression therapy use, and avoided a potential selection bias from loss to follow up. As patients in the PPI group were sicker at baseline, the lack of association between PPI use and increased risk of adverse renal outcomes is less likely to have been influenced by confounding variables.

Our study had several limitations as well. Similar to other observational studies, we were not able to confirm medication compliance or whether or not there was additional PPI use over the counter. Additionally, retrospective analyses are prone to residual confounding. While we included several variables that could affect mortality, we lacked details about nutritional data and albuminuria. Further, our patients have been followed in a health care system and hence these data might not be applicable to the community-dwelling adults with CKD. Finally, though including at least 2 PCP visits as an inclusion criterion helped minimize selection bias, it also reduced our sample size; therefore potentially making our findings less significant.

In summary, the use of PPI in a CKD population was not associated with increased risk of CKD progression compared to the use of $\mathrm{H} 2 \mathrm{~B}$ and to no acid-suppression therapy. More prospective research is needed to solidify those results and to identify the safety of PPI in CKD populations.

\section{Declarations}

Ethics approval and consent to participate: All methods were carried out in accordance with IRB guidelines. Need for consent was waived.

Consent for publication: Not applicable.

Availability of data and materials: All data analyzed during the this study are included in this published article.

Competing interests: The authors declare that they have no competing interests.

Funding: None.

\section{Authors' contributions:}

- Conceptualization: Ali Mehdi, Remy Daou, Nazih L. Nakhoul, Georges N. Nakhoul

- Methodology: Tarek Ashour, Jonathan J. Taliercio, Nazih L. Nakhoul, Georges N. Nakhoul

- Data acquisition/interpretation: Liza Cholin, Susana Arrigain, Jesse Schold

- Statistical analysis: Susana Arrigain, Jesse Schold

- Supervision/mentorship: Georges N. Nakhoul, Joseph Nally 
- Writing/Editing: Liza Cholin, Tarek Ashour, Ali Mehdi, Jonathan J. Taliercio, Remy Daou, Susana Arrigain, Jesse Schold, George Thomas, Joseph Nally, Nazih L. Nakhoul, Georges N. Nakhoul

Each author contributed important intellectual content during manuscript drafting or revision, accepts personal accountability for the author's own contributions, and agrees to ensure that questions pertaining to the accuracy or integrity of any portion of the work are appropriately investigated and resolved.

\section{Acknowledgements: None.}

\section{Authors' information (optional): None.}

\section{References}

1. Al-Aly Z, Maddukuri G, Xie Y. Proton Pump Inhibitors and the Kidney: Implications of Current Evidence for Clinical Practice and When and How to Deprescribe. Am J Kidney Dis. 2020;75(4):497-507. doi:10.1053/j.ajkd.2019.07.012

2. Brewster UC, Perazella MA. Proton pump inhibitors and the kidney: critical review. Clin Nephrol. 2007;68(2):65-72. doi:10.5414/cnp68065

3. Ruffenach SJ, Siskind MS, Lien YH. Acute interstitial nephritis due to omeprazole. Am J Med. 1992;93(4):472-473. doi:10.1016/0002-9343(92)90181-a

4. Härmark $L$, van der Wiel $H E$, de Groot MC, van Grootheest AC. Proton pump inhibitor-induced acute interstitial nephritis. Br J Clin Pharmacol. 2007;64(6):819-823. doi:10.1111/j.13652125.2007.02927.x

5. Antoniou T, Macdonald EM, Hollands S, et al. Proton pump inhibitors and the risk of acute kidney injury in older patients: a population-based cohort study. CMAJ Open. 2015;3(2):E166-E171. Published 2015 Apr 2. doi:10.9778/cmajo.20140074

6. Blank ML, Parkin L, Paul C, Herbison P. A nationwide nested case-control study indicates an increased risk of acute interstitial nephritis with proton pump inhibitor use. Kidney Int. 2014;86(4):837-844. doi:10.1038/ki.2014.74

7. Hart E, Dunn TE, Feuerstein S, Jacobs DM. Proton Pump Inhibitors and Risk of Acute and Chronic Kidney Disease: A Retrospective Cohort Study. Pharmacotherapy. 2019;39(4):443-453. doi:10.1002/phar.2235

8. Qiu T, Zhou J, Zhang C. Acid-suppressive drugs and risk of kidney disease: A systematic review and meta-analysis [published online ahead of print, 2018 Apr 12]. J Gastroenterol Hepatol. 2018;10.1111/jgh.14157. doi:10.1111/jgh.14157

9. Nochaiwong S, Ruengorn $C$, Awiphan R, et al. The association between proton pump inhibitor use and the risk of adverse kidney outcomes: a systematic review and meta-analysis. Nephrol Dial Transplant. 2018;33(2):331-342. doi:10.1093/ndt/gfw470

10. Arora P, Gupta A, Golzy M, et al. Proton pump inhibitors are associated with increased risk of development of chronic kidney disease. BMC Nephrol. 2016;17(1):112. Published 2016 Aug 3. 
doi:10.1186/s12882-016-0325-4

11. Lazarus B, Chen Y, Wilson FP, et al. Proton Pump Inhibitor Use and the Risk of Chronic Kidney Disease. JAMA Intern Med. 2016;176(2):238-246. doi:10.1001/jamainternmed.2015.7193

12. Xie Y, Bowe B, Li T, Xian H, Balasubramanian S, Al-Aly Z. Proton Pump Inhibitors and Risk of Incident CKD and Progression to ESRD. J Am Soc Nephrol. 2016;27(10):3153-3163. doi:10.1681/ASN.2015121377

13. Klatte DCF, Gasparini A, Xu H, et al. Association Between Proton Pump Inhibitor Use and Risk of Progression of Chronic Kidney Disease. Gastroenterology. 2017;153(3):702-710. doi:10.1053/j.gastro.2017.05.046

14. Rodríguez-Poncelas A, Barceló MA, Saez M, Coll-de-Tuero G. Duration and dosing of Proton Pump Inhibitors associated with high incidence of chronic kidney disease in population-based cohort. PLoS One. 2018;13(10):e0204231. Published 2018 Oct 17. doi:10.1371/journal.pone.0204231

15. Nochaiwong S, Ruengorn $C$, Awiphan R, et al. The association between proton pump inhibitor use and the risk of adverse kidney outcomes: a systematic review and meta-analysis. Nephrol Dial Transplant. 2018;33(2):331-342. doi:10.1093/ndt/gfw470

16. Grant $\mathrm{CH}$, Gillis KA, Lees JS, Traynor JP, Mark PB, Stevens KI. Proton pump inhibitor use and progression to major adverse renal events: a competing risk analysis. QJM. 2019;112(11):835-840. doi:10.1093/qjmed/hcz166

17. Navaneethan SD, Jolly SE, Schold JD, Arrigain S, Saupe W, Sharp J, Lyons J, Simon JF, Schreiber MJ Jr, Jain A, Nally JV Jr Clin J Am Soc Nephrol. 2011 Jan; 6(1):40-9.

18. Levey AS, Stevens LA, Schmid CH, Zhang YL, Castro AF 3rd, Feldman HI, Kusek JW, Eggers P, Van Lente F, Greene T, Coresh J, CKD-EPI (Chronic Kidney Disease Epidemiology Collaboration). Ann Intern Med. 2009 May 5; 150(9):604-12.

19. Fine JP, Gray RJ. A Proportional Hazards Model for the Subdistribution of a Competing Risk. J Am Stat Assoc. 1999;94(446):496-509

20. Tvingsholm SA, Dehlendorff C, Østerlind K, Friis S, Jäättelä M. Proton pump inhibitor use and cancer mortality. Int J Cancer. 2018;143(6):1315-1326. doi:10.1002/ijc.31529

21. De Roza MA, Kai L, Kam JW, et al. Proton pump inhibitor use increases mortality and hepatic decompensation in liver cirrhosis. World J Gastroenterol. 2019;25(33):4933-4944. doi:10.3748/wjg.v25.i33.4933

22. Hamai $\mathrm{K}$, Iwamoto $\mathrm{H}$, Ohshimo $\mathrm{S}$, et al. Use of proton pump inhibitors is associated with increased mortality due to nosocomial pneumonia in bedridden patients receiving tube feeding. Geriatr Gerontol Int. 2018;18(8):1215-1218. doi:10.1111/ggi.13450

23. Brozek W, Reichardt B, Zwerina J, Dimai HP, Klaushofer K, Zwettler E. Use of proton pump inhibitors and mortality after hip fracture in a nationwide study. Osteoporos Int. 2017;28(5):1587-1595. doi:10.1007/s00198-017-3910-x

24. Xie Y, Bowe B, Yan Y, Xian H, Li T, Al-Aly Z. Estimates of all cause mortality and cause specific mortality associated with proton pump inhibitors among US veterans: cohort study. BMJ. 


\section{Figures}

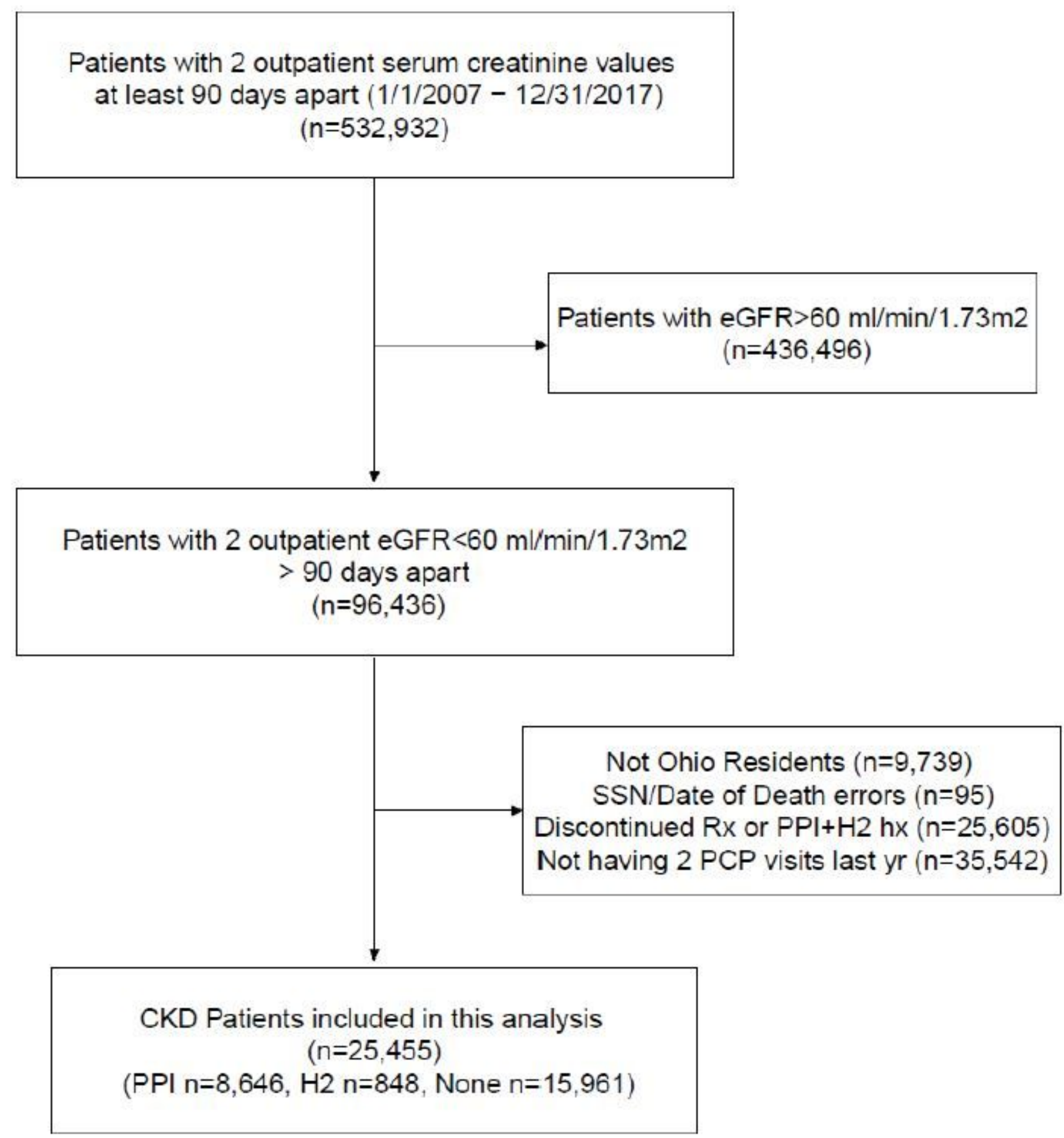

Figure 1

Flow chart of selection criteria 


\section{Death and ESKD}

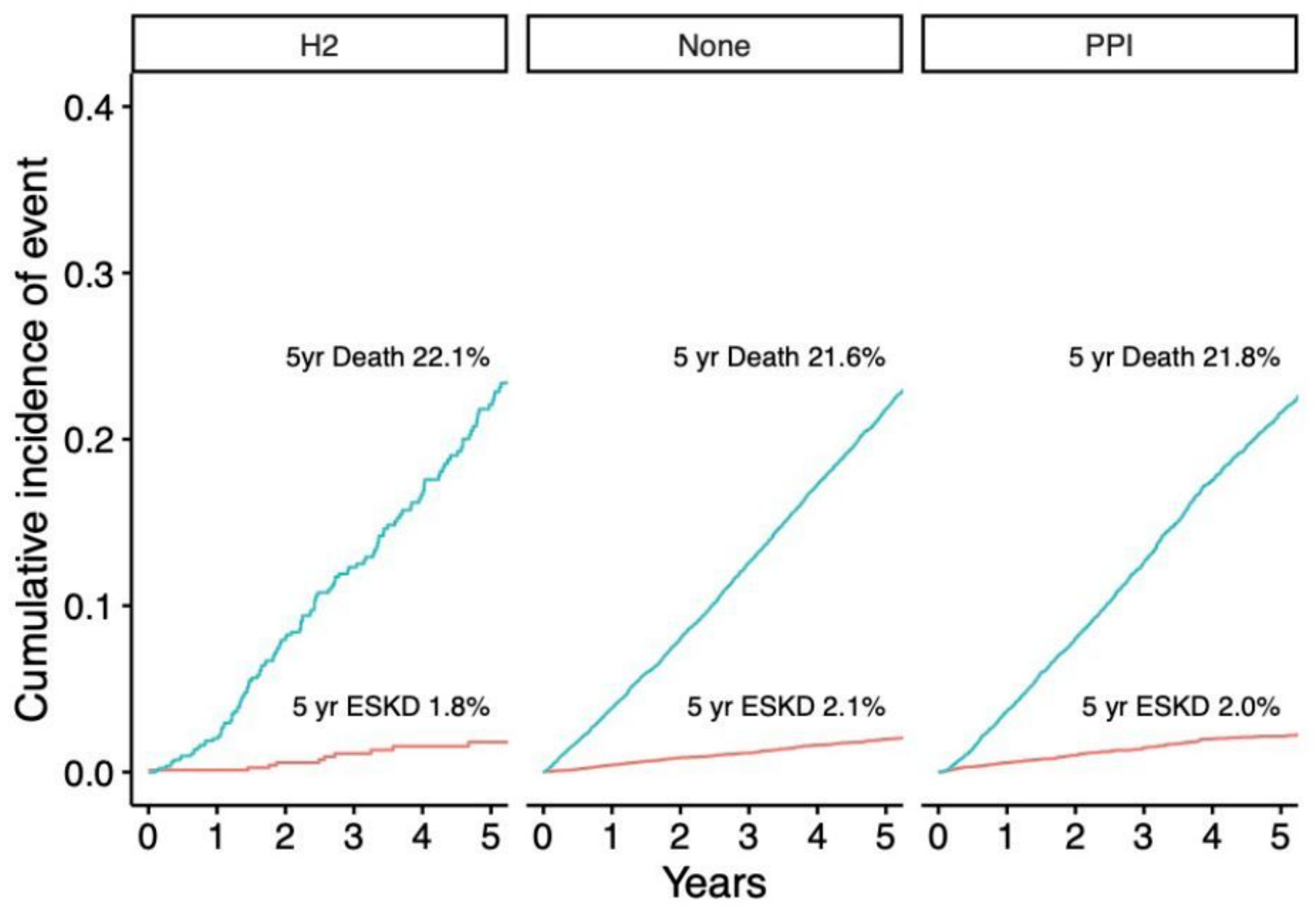

Figure 2

Graph depicting risk of death and ESKD amongst different medication groups 